\title{
Risk assessment of workers exposed to noise pollution in a textile plant
}

\author{
${ }^{1 *}$ M. Mohammadi Roozbahani; ${ }^{2}$ P. Nassiri; ${ }^{3}$ P. Jafari Shalkouhi \\ ${ }^{1}$ Department of Environmental Science, Graduate School of the Environment, Science and Research Branch, \\ Islamic Azad University, Ahvaz, Iran \\ ${ }^{2}$ Department of Occupational Health, the School of Public Health, Tehran University of Medical Sciences, \\ Tehran, Iran \\ ${ }^{3}$ Department of Environmental Engineering, Graduate School of the Environment and Energy, Science and \\ Research Branch, Islamic Azad University, Tehran, Iran
}

Received 5 September 2008; $\quad$ revised 25 July 2009; accepted 23 August 2009; $\quad$ available online 1 September 2009

\begin{abstract}
In order to assess the risks associated with worker's hearing loss, due to exposure to noise pollution, at the Boroujerd Textile Factory a cross sectional study was conducted. 60 workers from the Spinning and Weaving workshops and official staff were randomly selected as case and control groups and their hearing were tested by audiometry. The audiometric results revealed that amongst workers being exposed to the noise pollution in the Spinning and Weaving Workshops there is a distinct increase in the number of cases of hearing loss at high frequencies. There also appears to be a slight bias towards hearing loss in the left ear, in preference to the right in addition, those who have worked for longer than 16 years are subjected to hearing loss even at low frequencies conversely, the office workers (the control group) seem to suffer little or no hearing loss at low frequencies at all, but after approximately 10 years of service there may be some hearing loss, but only at higher frequencies, which could be attributed to presbycusis. Also, the t-test (statistical hypothesis test) results verified the significant difference among both groups at high frequencies. The questionnaire results indicated that workers feel symptoms such as headache, no sense centralization, excitement, nervousness, vertigo. Hence, controlling procedures seem to be essential to protect workers from noise disorders.
\end{abstract}

Keywords: Audiometry; Hearing loss; Occupational noise; Risk assessment; Spinning and weaving

\section{INTRODUCTION}

With respect to population growth, it is inevitable that there will be an increasing need for more technology and industrial development in order to provide the needs of evolving communities. Mechanization of common processes enables creation of time-saving production lines, which contain inherent risks. In the context of the work place a risk may be defined as a procedure in a position that identifies with the possibility of injury (Bhattachrya et al., 1981). The most notable risk related to the textile industry is exposure, in particular over exposure, to noise pollution, which depend on the time of exposure, noise intensity, frequency and individual sensitivity can reduce the hearing threshold temporarily or in the worst cases permanently. There are multiple recorded cases of worker bodily and psychic disorders caused by

凶*Corresponding Author Email: Mmohammadiroozbahani@yahoo.com Tel.: +98662 262 9748; Fax: +98662 2626677 exposure to excessive noise pollution (Giardino and Durkt, 1996). There are many other effects caused by extended exposure to noise pollution, including agitation, constant weariness, disorientation, headaches, vertigo, hypertension, cardioarrythmia and nervous and psychic disorders (Van Kempen et al., 2002). Diseases such as measles, mumps, scarlet fever, diphtheria, whooping cough, influenza, and certain other viral infections can lead to sensori-neural hearing loss. The processes of these diseases can have a toxic effect on the sensitive nerve endings in the cochlea. Infections of the cerebrospinal fluid such as meningitis can also cause damage to the cochlea. Tumorous growths near the auditory nerve can cause sensorineural hearing loss due to pressure on the nerve (Newby, 1972).

Laboratory studies have revealed that excessive noise may reduce social interaction, social 
responsibility and verbal disinhibition, diminish helping behavior and increase aggressive response (Geen and Powers, 1971; Sherrod and Downs, 1974; Matthews and Cannon, 1975). Task complexity has been identified in numerous experiments as a crucial determinant of the effects of noise on performance. Noise exposure usually leaves simple routine tasks unaffected and can even improve performance of monotonous tasks, presumably by elevating one's level of arousal (Broadbent, 1971). Besides hearing loss, noise may cause some after effects leaving workplace and exposure to noise pollution. The most common aftereffect appearing in the experimental literature is a reduced tolerance for frustration, manifested in a series of experiments as a reduction in willingness to persist in trying to solve insoluble puzzles (Glass and Singer, 1972; Percival and Loeb, 1980). Study on American adults (3638 people) in 1998 revealed that $48 \%$ of U.S. adults believe that they have suffered some hearing loss, including $35 \%$ of those 18 to 29 years old. $48 \%$ of adults know that hearing loss is not part of growing old, and $79 \%$ believe that hearing loss can interfere with a person's social life and personal relationships. $32 \%$ of adults say that while they regularly use noisy equipment around the house (e.g., lawn mower or vacuum cleaner), they do not believe that their use of this equipment could damage their hearing. Only $39 \%$ of adults have had a hearing test in the last three years. $21 \%$ of those over 65 years old say that they have never had a hearing test. Only $56 \%$ of adults in the United States believe that hearing tests are readily available to them. Only $51 \%$ of those who work in so-called "blue collar" occupations believe that hearing tests are readily accessible to them. These are people who work in an environment with a great deal of noise i.e. precision production, farmers, and machine operators (NIOSH, 1998). Bedi (2006) investigated occupational environment of textile industry and his findings revealed that noise level in certain section of the plants i.e. Loom Shed, Spinning and Ring Frame was higher than the acceptable limit of $90 \mathrm{dBA}$ for $8 \mathrm{~h}$ exposure according to OSHA in addition, the noise level in other sections such as: carding, blow room, combing etc., although was less than $90 \mathrm{dBA}$, but it was quite higher than limits used for assessment of noise for community response. Also, octave band analysis of the noise indicated the presence of high sound level in $4 \mathrm{kHz}$ which can induce hearing loss (Bedi, 2006).
Yildirim et al. (2007) observed that mean pure tone audiometric thresholds in textile workers were significantly higher than in control subjects at frequencies $2,000,4,000$ and $6,000 \mathrm{~Hz}(p<0.05)$. Hearing losses were more evident at high frequencies (4-6 kHz) than at low frequencies in worker group $(p<0.05)$. Also textile workers with longer employment duration had poorer hearing thresholds and the hearing loss had started on those who had worked for 5-8 y (Yildirim et al., 2007).

Ertem et al. (1998) studied on the hearing of 260 textile workers exposed to noise levels between 85-95 $\mathrm{dBA}$ in carpet and cotton textile factories by means of air and bone conductance audiograms obtained. The subjects were grouped into five hearing categories according to hearing thresholds at 125 to $8000 \mathrm{~Hz}$ with Klockhoffs classification. The prevalence of the grade- 3 hearing loss was $47.92 \%$ and grade $4-5$ was $9.21 \%$ on exposed subjects in both factories. There was significant difference between exposed and unexposed control subjects working in the same factories ( $\mathrm{p}<0.001)$ (Ertem et al., 1998). Hearing loss induced by noise exposure in a large scale textile mill (number of workers $=1,611$ ) in Thailand was investigated by Chavalitsakulchai et al. (1989). Their findings indicated that noise-induced hearing loss among workers in the weaving section was significantly higher than other mill workers and office workers ( $\mathrm{P}<0.01)$ (Chavalitsakulchai et al., 1989).

The Boroujerd textile factory is the newest one situated in the southwest of Iran and has a population of 1100 , although it is a modern factory, but the workers always object to the bad conditions that arise from noise pollution. Hence, this research which was carried out in 2007 focuses on the audiometric responses of workers in the spinning and weaving workshops and relates the average of hearing threshold and length of exposure.

\section{MATERIALS AND METHODS}

In order to evaluate the effects of noise on textile industry workers, it was necessary to specify a statistical sample consisting of individuals who are exposed to noise constantly during their work shift. The case group was randomly selected from the spinning and weaving workshops, with noise level above the standard $85 \mathrm{dBA}$ for $8 \mathrm{~h}$ exposure (ACGIH, 2007). Noise pollution was measured in each workshop: Phase 1 Spinning Workshop 97 dBA, Phase 2 Spinning 
Workshop 90 dBA, Phase 1 Weaving Workshop 100 dBA and Phase 2 Weaving Workshop $99 \mathrm{dBA}$. The case group comprised of 40 workers from the Spinning and Weaving workshops from of Phases 1 and 2 who had worked for four different job history: $\leq 5,6-10,11-15$ and $\geq 16$ y. This group was compared to a control group comprising of 20 staff officers, with similar employment records and age.

Table 1: Audiometric test results based on the records of the case group in spinning and weaving workshops

\begin{tabular}{|c|c|c|c|c|c|c|c|c|c|c|c|c|c|c|}
\hline \multirow{3}{*}{ Number } & \multirow{3}{*}{$\begin{array}{l}\text { Mean } \\
\text { of } \\
\text { records } \\
\text { (year) }\end{array}$} & \multirow{3}{*}{ Ear } & \multicolumn{12}{|c|}{ Hearing loss in different frequencies $(\mathrm{Hz})$} \\
\hline & & & \multicolumn{2}{|c|}{250} & \multicolumn{2}{|c|}{500} & \multicolumn{2}{|c|}{1000} & \multicolumn{2}{|c|}{2000} & \multicolumn{2}{|c|}{4000} & \multicolumn{2}{|c|}{8000} \\
\hline & & & Mean & SD & Mean & $\mathrm{SD}$ & Mean & SD & Mean & SD & Mean & SD & Mean & $\mathrm{SD}$ \\
\hline \multirow{2}{*}{5} & \multirow{2}{*}{$\leq 5$} & Right & 10 & 0 & 10 & 0 & 10 & 0 & 10 & 0 & 15 & 4.47 & 28 & 21.6 \\
\hline & & Left & 10 & 0 & 10 & 0 & 12 & 4.47 & 15 & 4.47 & 16 & 13.41 & 26 & 26.07 \\
\hline \multirow{2}{*}{5} & \multirow{2}{*}{$6-10$} & Right & 10 & 0 & 10 & 0 & 20 & 8.94 & 20 & 17.3 & 18 & 8.36 & 20 & 10 \\
\hline & & Left & 10 & 0 & 10 & 0 & 16 & 8.94 & 22 & 8.36 & 20 & 8.9 & 34 & 16.7 \\
\hline \multirow{2}{*}{5} & \multirow{2}{*}{$11-15$} & Right & 10 & 0 & 10.83 & 2.88 & 15 & 3.89 & 17.5 & 12.1 & 31.6 & 16.42 & 35 & 26.45 \\
\hline & & Left & 20 & 21.37 & 17.5 & 16.02 & 15 & 9.04 & 23 & 11.64 & 38 & 13.37 & 39 & 21.88 \\
\hline \multirow{2}{*}{5} & \multirow{2}{*}{$\geq 16$} & Right & 12.72 & 9.04 & 16 & 9.24 & 16.36 & 12.06 & 21 & 9.24 & 39.09 & $14 / 45$ & 30 & 14.14 \\
\hline & & Left & 17.27 & 16.18 & 15.45 & 12.13 & 16.36 & 12.06 & 23 & 10.44 & 35 & 11.28 & 35 & 14.86 \\
\hline
\end{tabular}

Table 2: Audiometric test results based on the records of the control group in textile plant

\begin{tabular}{|c|c|c|c|c|c|c|c|c|c|c|c|c|c|c|}
\hline \multirow{3}{*}{ Number } & \multirow{3}{*}{$\begin{array}{l}\text { Mean } \\
\text { of } \\
\text { records } \\
\text { (year) }\end{array}$} & \multirow{3}{*}{ Ear } & \multicolumn{12}{|c|}{ Hearing loss in different frequencies $(\mathrm{Hz})$} \\
\hline & & & \multicolumn{2}{|c|}{250} & \multicolumn{2}{|c|}{500} & \multicolumn{2}{|c|}{1000} & \multicolumn{2}{|c|}{2000} & \multicolumn{2}{|c|}{4000} & \multicolumn{2}{|c|}{8000} \\
\hline & & & Mean & SD & Mean & SD & Mean & SD & Mean & SD & Mean & SD & Mean & SD \\
\hline \multirow{2}{*}{5} & \multirow{2}{*}{$\leq 5$} & Right & 10 & 0 & 10 & 0 & 10 & 0 & 10 & 0 & 10 & 0 & 10 & 0 \\
\hline & & Left & 10 & 0 & 10 & 0 & 10 & 0 & 10 & 0 & 10 & 0 & 10 & 0 \\
\hline \multirow{2}{*}{5} & \multirow{2}{*}{$6-10$} & Right & 10 & 0 & 10 & 0 & 10 & 0 & 10 & 0 & 13 & 11.57 & 10 & 0 \\
\hline & & Left & 10 & 0 & 10 & 0 & 10 & 0 & 10 & 0 & 10 & 0 & 10 & 0 \\
\hline \multirow{2}{*}{5} & \multirow{2}{*}{$11-15$} & Right & 10 & 0 & 10 & 0 & 10 & 0 & 10 & 0 & 30 & 14.14 & 15 & 7.07 \\
\hline & & Left & 10 & 0 & 10 & 0 & 10 & 0 & 10 & 0 & 20 & 14.14 & 10 & 0 \\
\hline \multirow{2}{*}{5} & \multirow{2}{*}{$\geq 16$} & Right & 10 & 0 & 10 & 0 & 10 & 0 & 10 & 0 & 20 & 15.75 & 20 & 10 \\
\hline & & Left & 10 & 0 & 10 & 0 & 10 & 0 & 10 & 0 & 25 & 5.77 & 17 & 11.54 \\
\hline
\end{tabular}

Table 3: T test results on the case and control groups hearing loss with job history of $\leq 5 \mathrm{y}$

\begin{tabular}{|c|c|c|c|c|c|c|c|c|c|c|c|c|}
\hline $\begin{array}{l}\mathrm{f}(\mathrm{Hz}) \\
\text { Ear }\end{array}$ & \multicolumn{2}{|c|}{250} & \multicolumn{2}{|c|}{500} & \multicolumn{2}{|c|}{1000} & \multicolumn{2}{|c|}{2000} & \multicolumn{2}{|c|}{4000} & \multicolumn{2}{|c|}{8000} \\
\hline & $\begin{array}{r}\text { case } \\
10\end{array}$ & $\begin{array}{c}\text { control } \\
10\end{array}$ & $\begin{array}{l}\text { case } \\
10\end{array}$ & $\begin{array}{c}\text { control } \\
10\end{array}$ & $\begin{array}{c}\text { case } \\
10\end{array}$ & $\begin{array}{c}\text { control } \\
10\end{array}$ & $\begin{array}{c}\text { case } \\
10\end{array}$ & $\begin{array}{l}\text { control } \\
10\end{array}$ & $\begin{array}{c}\text { case } \\
15\end{array}$ & $\begin{array}{c}\text { control } \\
10\end{array}$ & $\begin{array}{c}\text { case } \\
28\end{array}$ & $\begin{array}{c}\text { control } \\
10\end{array}$ \\
\hline Right & & & & & & & \multicolumn{6}{|c|}{$\mathrm{P}=0.05$} \\
\hline & $\begin{array}{l}\text { case } \\
10\end{array}$ & $\begin{array}{c}\text { control } \\
10\end{array}$ & $\begin{array}{c}\text { case } \\
10\end{array}$ & $\begin{array}{c}\text { control } \\
10\end{array}$ & $\begin{array}{l}\text { case } \\
12\end{array}$ & $\begin{array}{c}\text { control } \\
10\end{array}$ & $\begin{array}{c}\text { case } \\
15\end{array}$ & $\begin{array}{c}\text { control } \\
10\end{array}$ & $\begin{array}{c}\text { case } \\
16\end{array}$ & $\begin{array}{c}\text { control } \\
10\end{array}$ & $\begin{array}{c}\text { case } \\
26\end{array}$ & $\begin{array}{l}\text { control } \\
10\end{array}$ \\
\hline Left & & & & & & & \multicolumn{2}{|c|}{$\mathrm{P}=0.05$} & \multicolumn{2}{|c|}{$\mathrm{P}=0.05$} & & \\
\hline
\end{tabular}

Table 4: $\mathrm{T}$ test results on the case and control groups hearing loss with 6-10 y job history

\begin{tabular}{|c|c|c|c|c|c|c|c|c|c|c|c|c|}
\hline $\begin{array}{c}\mathrm{f}(\mathrm{Hz}) \\
\text { Ear }\end{array}$ & \multicolumn{2}{|c|}{250} & \multicolumn{2}{|c|}{500} & \multicolumn{2}{|c|}{1000} & \multicolumn{2}{|c|}{2000} & \multicolumn{2}{|c|}{4000} & \multicolumn{2}{|c|}{8000} \\
\hline \multirow{5}{*}{ Right } & case & control & case & control & case & control & case & control & case & control & case & control \\
\hline & 10 & 10 & 10 & 10 & 20 & 10 & 20 & 10 & 18 & 13 & 20 & 10 \\
\hline & & & & & & & & & & & \multicolumn{2}{|c|}{$\mathrm{P}=0.05$} \\
\hline & case & control & case & control & case & control & case & control & case & control & case & control \\
\hline & 10 & 10 & 10 & 10 & 16 & 10 & 22 & 10 & 20 & 10 & 34 & 10 \\
\hline Left & & & & & & & \multicolumn{2}{|c|}{$\mathrm{P}=0.01$} & & $=0.05$ & \multicolumn{2}{|c|}{$\mathrm{P}=0.01$} \\
\hline
\end{tabular}


Audiometric tests were performed on all the identified workers and separated into the four aforementioned employment period groups. The audiometric results were age-corrected. Correlations between period of exposure and degree of hearing impairment in 6 frequency bands for both left and right ears are presented along with $\mathrm{T}$ test statistical analysis. Worker perception of the degree of noise pollution has also been collected using questionnaires and assessed using $\chi^{2}$ testing (EPA, 1981; Dixon and Massey, 1983; Berger et al., 1986).

\section{RESULTS AND DISCUSSION}

Results from the audiometric tests, for 6 frequency bands, on the case and control groups are presented in Tables 1 and 2. The $\mathrm{T}$ test results for each employment group are presented in Tables 3-6.

As shown in Table 1, the Mean hearing loss in high frequencies is considerable however, among the workers who have worked for 11-15 and more than 16 $\mathrm{y}$, the Mean hearing loss is more considerable in all frequencies. Results from audiometric tests among the official staffs indicated that up to $4 \mathrm{kHz}$ the Mean hearing loss is constant and only in $4 \mathrm{kHz}$ and $8 \mathrm{kHz}$ it is considerable which depends on the records of the official staffs too (Table 2). As shown in Table 3, there is a statistically significant difference between hearing loss of both ears of the case and control groups in 4 $\mathrm{kHz}(\mathrm{P}=0.05)$. Also, there is a statistically significant difference between hearing loss of left ear of the case and control groups in $2 \mathrm{kHz}(\mathrm{P}=0.05)$. According to Table 4 in $8 \mathrm{kHz}$, there is a statistically significant difference between hearing loss of left ear of the case and control groups $(\mathrm{P}=0.01)$ and for right ear of the workers $P_{\text {value }}=0.05$ was obtained. There is a statistically significant difference between hearing loss of left ear of both groups $(\mathrm{P}=0.05)$ in $4000 \mathrm{~Hz}$. As well as, in 2 $\mathrm{kHz}$ for left ear of both groups $\mathrm{P}_{\text {value }}=0.01$ was obtained that indicates significant difference between hearing loss of both groups. Table 5 shows the meaningful difference between hearing loss of left and right ear of the case and control groups in $2 \mathrm{kHz}(\mathrm{P}=0.05)$ and also according to Table 5, for left ear in $4 \mathrm{kHz}, \mathrm{P}_{\text {value }}=0.05$ and in $8 \mathrm{kHz}, \mathrm{P}_{\text {value }}=0.01$ were determined. According to Table 6 for right ear of the workers of both groups $\mathrm{P}_{\text {value }}=0.05$ was observed $(500,2000$ and $4000 \mathrm{~Hz})$ and in $8 \mathrm{kHz}$ for left ear $\mathrm{P}_{\text {value }}=0.05$ was determined. Therefore, these findings verify meaningful difference between hearing loss of the workers in relevant frequencies. The audiometric results in Tables 1 and 2 indicate that amongst workers being exposed to the noise pollution in the Spinning and Weaving Workshops there is a distinct increase in the number of cases of hearing loss above $1 \mathrm{kHz}$.

Table 5: T test results on the case and control groups hearing loss with 11-15 y job history

\begin{tabular}{|c|c|c|c|c|c|c|c|c|c|c|c|c|}
\hline $\begin{array}{c}\mathrm{f}(\mathrm{Hz}) \\
\text { Ear }\end{array}$ & \multicolumn{2}{|c|}{250} & \multicolumn{2}{|c|}{500} & \multicolumn{2}{|c|}{1000} & \multicolumn{2}{|c|}{2000} & \multicolumn{2}{|c|}{4000} & \multicolumn{2}{|c|}{8000} \\
\hline & case & control & case & control & case & control & case & control & case & control & case & control \\
\hline & 10 & 10 & 10.83 & 10 & 15 & 10 & 17.5 & 10 & 31.6 & 30 & 35 & 15 \\
\hline \multirow[t]{3}{*}{ Right } & & & \multicolumn{10}{|c|}{$\mathrm{P}=0.05$} \\
\hline & case & control & case & control & case & control & case & control & case & control & case & control \\
\hline & 20 & 10 & 17.5 & 10 & 15 & 10 & 23 & 10 & 38.3 & 20 & 39 & 10 \\
\hline Left & & & & & & & & 0.05 & & 0.05 & & 0.01 \\
\hline
\end{tabular}

Table 6: T test results on the case and control groups hearing loss with job history of $\geq 16$ years

\begin{tabular}{|c|c|c|c|c|c|c|c|c|c|c|c|c|}
\hline $\mathrm{f}(\mathrm{Hz})$ & \multicolumn{2}{|c|}{250} & \multicolumn{2}{|c|}{500} & \multicolumn{2}{|c|}{1000} & \multicolumn{2}{|c|}{2000} & \multicolumn{2}{|c|}{4000} & \multicolumn{2}{|c|}{8000} \\
\hline & case & control & case & control & case & control & case & control & case & control & case & control \\
\hline & 12.72 & 10 & 16 & 10 & 16.36 & 10 & 21 & 10 & 39.09 & 20 & 30 & 20 \\
\hline \multirow[t]{3}{*}{ Right } & \multicolumn{6}{|c|}{$\mathrm{P}=0.05$} & \multicolumn{2}{|c|}{$\mathrm{P}=0.05$} & \multicolumn{2}{|c|}{$\mathrm{P}=0.05$} & & \\
\hline & case & control & case & control & case & control & case & control & case & control & case & control \\
\hline & 17 & 35 & 25 & 38 & 10 & 23 & 10 & 16.36 & 10 & 15.45 & 10 & 17.27 \\
\hline Left & & & & & & & & & & & \multicolumn{2}{|c|}{$\mathrm{P}=0.05$} \\
\hline
\end{tabular}


There also appears to be a slight bias towards hearing loss in the left ear, in preference to the right. Those who have worked for longer than $16 \mathrm{y}$ are subjected to hearing loss even at low frequencies; which is realistic in that increased exposure will affect the ear drums in an increasingly more adverse manner. Initially hearing is lost at high frequencies and then upon more exposure the hearing loss deteriorates to the extent that it is difficult to differentiate sounds even at low frequencies. By comparison the office workers (the control group) seem to suffer little or no hearing loss below $2 \mathrm{kHz}$ at all, but after approximately $10 \mathrm{y}$ of service there may be some hearing loss, but only at higher frequencies, which could be attributed to presbycusis. The t-test presented in Tables 3-6 corroborate the results presented in Tables 1 and 2 in as much as there appears to be a slight bias towards hearing loss in the left ear and the workers on the workshop floor have a greater degree of hearing impairment than those in the offices. After analyzing the questionnaires, it identified that the environmental noise for $92 \%$ of case group (spinning and weaving workers) is persecutor. About $85 \%$ of workers have temporary headache and $10 \%$ have permanent headache. $55 \%$ of workers have no sense centralization. In $63 \%$ of workers, the noise make speech interference during talking the others, about $73 \%$ of them are involved in insomnia, $45 \%$ are involved in excitement and nervousness without any reason, about $90 \%$ have vertigo, about $65 \%$ of workers feel tinnitus in their ears during the vacation and out of work environment. At the end of work shift about $60 \%$ of workers feel heaviness in their ears and $40 \%$ have this sense in vacations and rest times and all these symptoms show the temporary and permanent loss of hearing threshold and risks that exist by noise of industry. Industrial noise may have the most pronounced effects on performance including exhaustion, absentmindedness, mental strain, absenteeism, tenseness, and irritability. All of these factors affect worker efficiency (HEW and NIOSH, 1972). It is reasonable to suppose that increased absenteeism can come from workers' psychological aversion to returning each day to an unpleasant, noisy working environment. The frequency and severity of industrial injuries could tend to be higher in noisy environments because of masking of warning signals and of increases in momentary gaps or errors in performance (EPA, 1976).

Moreover, research has shown that the motivational involvement of the individual influences the extent that noise will have on performance (Wilkinson, 1969). Other studies have shown that personality variables, primarily the trait of introversion/extroversion, can influence performance under noise (Blake, 1971; Discipio, 1971; Davies and Hockey, 1966). It is hoped that by training the workers to reserve their ears and with necessary actions for controlling and reducing the noise such as repairing and replacing the amortized machines, it can be effective to reduce the risk by performing the plans of controlling and reducing through protective programs for hearing for all persons who work in this industry (Lipscomb and Taylor, 1992; Nassiri and Golbabai, 1993; Lercher, 1996; Nguyen et al., 1998). In addition, absorptive materials can be used for the walls and floor which can attenuate background noise level and sound energy reflections. In addition, it is not possible to provide a definitive answer to the question whether protecting against hearing loss guarantees that no nonauditory physiological effects will occur. However, EPA-sponsored primate research has shown that significant and sustained elevations in blood pressure can be produced as a result of exposure to noise levels which do not produce any significant permanent hearing loss in the subjects (Peterson et al., 1981). These data would suggest that protecting against the auditory effects of noise does not necessarily prevent the nonauditory effects. Human data confirming this conclusion are needed (EPA, 1981). It can be concluded that hearing loss is not the only problem caused by occupational noise on the other hand, besides that, other physiological and even psychological effects of noise must be considered which can affect workers performance.

\section{ACKNOWLEDGMENTS}

The authors wish to appreciate Mr. Goudarzi (Manager of the research and development office of the Boroujerd Textile Plant) and also thank to Mr. Shalili (supervisor of the Health Center of the Factory) for their sincere assistances.

\section{REFERENCES}

ACGIH, (2007). Threshold limit value and biological exposure index, American Conference of Governmental Industrial Hygienist.

Bedi, R., (2006). Evaluation of occupational environment in two textile plants in northern India with specific reference to noise. Ind. Health., 44 (1), 112-116 (5 pages).

Berger, E. H.; Ward, W. D.; Morrill, J. C.; Royster, L. H., (1986). Noise and Hearing Conservation Manual, $4^{\text {th }}$ Ed. America Industrial Hygiene Associations.

Bhattacharya, S. K.; Saiyed, H. N.; Roy, A.; Chatterjee, S. K., (1981). Hearing acuity in weavers of a textile mill. Indian J. Med. Res., 74 (11), 779-785 (7 pages). 
Blake, M. J. F., (1971). Temperament and time of day. In Colquhoun, W. P. (Ed.), Biological Rhythms and Human Performance., London: Academic Press.

Broadbent, D. E., (1971). Decision and Stress. London and N.Y., Academic Press.

Chavalitsakulchai, P.; Kawakami, T.; Kongmuang, U.; Vivatjestsadawut, P.; Leongsrisook, W., (1989). Noise exposure and permanent hearing loss of textile workers in Thailand. Ind. Health., 27 (4), 165-173 (9 pages).

Davies, D. R.; Hockey, G. R. J., (1966). The effects of noise and doubling the signal frequency on individual differences in visual vigilance performance. British J. Psychol., 57 (3), 381-389 (9 pages)

Discipio, W. J., (1971). Psychomotor performance as a function of white noise and personality variables. Percept. Motor Skill., 33 (1), 82 (1 pages).

Dixon, J. D.; Massey, F. J., (1983). Introduction to statistical analysis, Mc Graw Hill.

EPA, (1976). Some considerations in choosing an occupational noise exposure regulation. U. S. Environmental Protection Agency, Office of Noise Abatement and Control.

EPA., (1981). Noise effects handbook: A desk reference to health and welfare effects of noise. EPA 500-9-82-106, U.S. Environmental Protection Agency, National Association of Noise Control Officials.

Ertem, M.; Ilcin, E.; Meric, F., (1998). Noise induced hearing loss among cotton textile and carpet mill workers. Tr. J. Med. Sci., 28 (5), 561-565 (5 pages).

Geen, R. G.; Powers, P. C., (1971). Shock and noise as instigating stimuli in human aggression. Psychologic. Rep., 28 (3), 983985 (3 pages).

Giardino, D. A.; Durkt, G. Jr., (1996). Evaluation of muff-type hearing protectors as in a working environment. Am. Ind. Hyg. Assoc. J., 57 (3), 264-271 (8 pages).

Glass, D. C.; Singer, J. E., (1972). Urban stress: Experiments on noise and social stressors. Academic Press. New York, USA.

HEW and NIOSH, (1972), U.S. Department of Health, Education, and Welfare, Public Health service, and the National Institute for Occupational Safety and Health. Industrial Noise and Worker Medical, Attendance and Accident Records.
Lercher, P., (1996). Environmental noise and health: An integrated research perspective. Environ. Int., 22 (1), 117129 (13 pages).

Lipscomb, D.; Taylor, A., (1992). Noise control. Handbook of principal and practices, Van Nostrad Rainhold Co.

Matthews, K. E.; Cannon, L. K., (1975). Environmental noise level as a determinant of helping behavior. J. Personal. Social Psychol., 32 (4), 571-577 (7 pages).

Nassiri, P.; Golbabai, F., (1993). The effect of noise induced hearing loss on dentists. Med. J. Iran., 7 (2), 83-86 (4 pages).

Newby, H. A., (1972). Audiology. Englewood Cliffs, Prentice Hall, Inc. New Jersey, USA.

Nguyen, A. L.; Nguyen, T. C.; Van, T. L.; Hoang, M. H.; Nguyen, S.; Jonai, H.; Villanueva, M. B.; Matsuda, S.; Sotoyama, M.; Sudo, A., (1998). Noise levels and hearing ability of female workers in a textile factory in Vietnam. Ind. Health, 36 (1), 61-65 (5 pages).

NIOSH, (1998). Noise-Induced hearing loss - attitudes and behaviors of U. S. Adults, available at: http://origin.cdc.gov/ niosh/topics/noise/abouthlp/nihlattitude.html

Percival, L.; Loeb, M., (1980). Influence of noise characteristics on behavioral aftereffects. Hum. Factors, 22 (3), 341-352 (12 pages).

Peterson, E. A.; Augenstein, J. S.; Tanis, D. C.; Augenstein, D. G., (1981). Noise raises blood pressure without impairing auditory sensitivity. Science, 211 (4489), 1450-1452 (3 pages).

Sherrod, D. R.; Downs, R., (1974). Environmental Determinants of Altruism: The Effect of Stimulus Overload and Perceived Control on Helping. J. Experiment. Soc. Psycho., 10 (5), 468-479 (12 pages).

Van Kempen, E. E. M. M.; Kruize, H.; Boshuizen, H. C.; Ameling, C. B.; Staatsen, B. A. M.; de Hollander, A. E. M., (2002). The association between noise exposure and blood pressure and ischemic heart disease: A meta-analysis. Environ. Health Perspect., 110 (3), 307-317 (11 pages).

Wilkinson, R. T., (1969). Some factors influencing the effects of environmental stressors upon performance. Psychologic. Bull., 72 (4), 260-272 (13 pages).

Yildirim, I.; Kilinc, M.; Okur, E.; Inanc Tolun, F.; Kilic, M. A.; Kurutas, E. B.; Ekerbicer, H. Ç., (2007). The effects of noise on hearing and oxidative stress in textile workers. Ind. Health., 45 (6), 743-749 (7 pages).

\section{AUTHOR (S) BIOSKETCHES}

Mohammadi Roozbahani, M., M.Sc., Department of Environmental Science, Graduate School of the Environment, Science and Research Branch, Islamic Azad University, Ahvaz, Iran and Ph.D. student, Department of Environmental Sciences, Graduate School of the Environment and Energy, Science and Research Branch, Islamic Azad University, Tehran, Iran. Email: Mmohammadiroozbahani@yahoo.com

Nassiri, P., Ph.D., Professor, Department of Occupational Health, the School of Public Health, Tehran University of Medical Sciences, Iran. Email: nassiri@sina.tums.ac.ir

Jafari Shalkouhi, P., M.Sc., Department of Environmental Engineering, Graduate School of the Environment and Energy, Science and Research Branch, Islamic Azad University, Tehran, Iran. Email: pedram121212@yahoo.com

How to cite this article: (Harvard style)

Mohammadi Roozbahani, M.; Nassiri, P.; Jafari Shalkouhi, P., (2009). Risk assessment of workers exposed to noise pollution in a textile plant. Int. J. Environ. Sci. Tech., 6 (4), 591-596. 